\title{
Blockade of the Type I Somatomedin Receptor Inhibits Growth of Human Breast Cancer Cells in Athymic Mice
}

\author{
Carlos L. Arteaga, Libbey J. Kitten, Ester B. Coronado, Steven Jacobs," Frederick C. Kull, Jr.," \\ D. Craig Allred, ${ }^{\ddagger}$ and C. Kent Osborne \\ Division of Medical Oncology and ${ }^{\ddagger}$ Department of Pathology, University of Texas Health Science Center at San Antonio, San Antonio, \\ Texas 78284; and *Wellcome Research Laboratories, Burroughs Wellcome Co., Research Triangle Park, North Carolina 27709
}

\begin{abstract}
Insulin and insulin-like growth factors (IGIs) stimulate the growth of human breast cancer cells in vitro. The type I somatomedin receptor (SR) expressed in these cells may mediate the growth effects of these peptides. We have examined the role of this receptor on human breast cancer growth with a monoclonal antibody ( $\alpha$-IR-3) that blocks the receptor binding domain and inhibits IGF-I-induced growth. $\alpha$-IR-3 inhibited clonal growth in vitro and blocked the mitogenic effect of exogenous IGF-I in both MCF-7 and MDA-231 breast cancer cell lines. Antibody-induced blockade of the type I SR also inhibited the estrogen-independent MDA-231 cells growing in vivo in nude mice, but growth of the estrogen-dependent MCF-7 cells was unaffected. IGIs are important growth regulators of MDA-231 breast cancer cells. Blockade of this growth stimulatory pathway may provide a new treatment strategy.
\end{abstract}

\section{Introduction}

Insulin and insulin-like growth factors (IGFs) ${ }^{1}$ stimulate the proliferation of cultured human breast cancer cells (1-6). Recently, breast cancer cells have been reported to synthesize and secrete IGF activities into the culture medium (5-7), suggesting that these polypeptides could function as both endocrine and autocrine/paracrine growth regulators (8). In estrogen receptor (ER)-positive cells, the expression and secretion of both IGF type I- and II-like proteins are increased by estrogen leading to the possibility that they contribute to estrogen-induced growth $(6,9)$.

It is assumed that IGF-I stimulates the growth of breast

This work was presented in part at the 70th Annual Meeting of the Endocrine Society in New Orleans, LA, 1988, and published in abstract form in the 1988 Meeting Proceedings, p. 191.

Dr. Arteaga's current address is Division of Medical Oncology, Vanderbilt University, VA Medical Center, 1310 24th Avenue South, Nashville, TN 37212.

Address reprint requests to Dr. Osborne, Department of Medicine, Division of Oncology University of Texas Health Science Center at San Antonio, 7703 Floyd Curl Drive, San Antonio, TX 78284-7884. 1989.

Received for publication 16 March 1989 and in revised form 17 July

1. Abbreviations used in this paper: EGF, epidermal growth factor; ER, estrogen receptor; IGF, insulin-like growth factor; IMEM, improved minimum essential medium; SR, somatomedin receptor.

J. Clin. Invest.

(c) The American Society for Clinical Investigation, Inc. $0021-9738 / 89 / 11 / 1418 / 06 \$ 2.00$

Volume 84, November 1989, 1418-1423 cancer cells via the type I somatomedin receptor (SR), also known as the IGF-I receptor (5-7). As shown in other systems, this receptor may also mediate some of the mitogenic effects of IGF-II and insulin (10-15). Furthermore, breast cancer tissue from patients exhibits higher IGF-I binding than adjacent normal tissue (16) suggesting a link between type I SR and breast epithelial cell transformation. If these peptides are important endocrine or autocrine/paracrine growth regulators, then blockade of this receptor might inhibit breast cancer growth. In the present study we have investigated the effect of blockade of the type I SR on cultured human breast cancer cells grown in vitro and in vivo as subcutaneous tumors in the athymic nude mouse.

\section{Methods}

Cells, hormones, and antibodies. The MCF-7 line was supplied by Dr. M. Lippman (National Cancer Institute) and the MDA-231 line was obtained from the American Type Culture Collection (Rockville, MD). Cells were cultured and passaged as previously described (17). Human recombinant IGF-I was purchased from Amgen Biologicals (Thousand Oaks, CA). ${ }^{125} \mathrm{I}$-IGF-I (sp act 2,125 Ci/mmol) was obtained from the Amersham Corp. (Arlington Heights, IL).

$\alpha$-IR-3 antibody is a mouse monoclonal $\operatorname{IgG}_{1}$ prepared after immunization with partially purified insulin receptors from human placenta (18). This antibody specifically blocks type I SR binding $(18,19)$. The mouse monoclonal $\alpha$-IR-1 antibody, which recognizes a nonbinding domain of the insulin receptor and has no biologic activity $(12,19)$, was used as a control. Purified antibody preparations contained no detectable endotoxin ( $<0.3 \mathrm{pg} / \mu \mathrm{g}$ by the Limulus ameba lysate test).

Binding studies. Breast cancer cells were grown in 24-well tissue culture plates (Corning Glass Works, Corning, NY). Once confluent, the monolayers were washed with binding buffer (improved minimum essential medium [IMEM], 0.1\% BSA, $25 \mathrm{mM}$ Hepes [Gibco Laboratories, Grand Island, NY], $\mathrm{pH} 7.4$ ) and incubated with $40 \mathrm{pM}^{125} \mathrm{I}-$ IGF-I plus various concentrations of unlabeled $\alpha$-IR-3 or IGF-I, for 90 $\mathrm{min}$ at room temperature. Monolayers were then washed three times with cold PBS/0.1\% BSA and solubilized with $0.5 \mathrm{~N} \mathrm{NaOH}$, and cellassociated radioactivity was measured in a gamma counter.

In vitro growth experiments. For anchorage-independent growth experiments, a single-cell suspension of $5 \times 10^{3}$ cells was cloned in $0.8 \%$ agarose as previously described (17) with different concentrations of $\alpha$-IR-3 or $\alpha$-IR-1. The dishes were incubated in a $5 \% \mathrm{CO}_{2}$ atmosphere at $37^{\circ} \mathrm{C}$ and colonies (measured $\geq 50 \mu \mathrm{m}$ ) were counted using an image analyzer (Omnicon model II, Bausch \& Lomb, Inc., Rochester, NY). For monolayer growth experiments, $30 \times 10^{3}$ cells per well were plated in 24-well tissue culture plates in IMEM supplemented with $5 \%$ fetal calf serum (FCS). After $24 \mathrm{~h}$, the medium was removed and replaced with phenol red-free serum-free IMEM alone or with IGF-I, $\alpha$-IR-3, or both. Medium with hormone and/or antibody was exchanged every $2 \mathrm{~d}$. Cell counts were determined after suspending the cells with $1 \mathrm{mM}$ EDTA $5 \mathrm{~d}$ after plating.

In vivo experiments. 3-wk-old female athymic mice (Harlan Sprague-Dawley, Madison, WI) were inoculated in the flank just cau- 
Table I. Effect of $\alpha-I R-3$ and $\alpha-I R-1$ on Anchorage-independent Growth of Breast Cancer Cells

\begin{tabular}{lcc}
\hline & MCF-7 & MDA-231 \\
\hline PBS & $194 \pm 24$ & $1098 \pm 28$ \\
$\alpha-$ IR-3 & & \\
$1.0 \mathrm{nM}$ & $115 \pm 38$ & $827 \pm 91$ \\
$10 \mathrm{nM}$ & $55 \pm 7$ & $550 \pm 37$ \\
$100 \mathrm{nM}$ & $34 \pm 10$ & $488 \pm 57$ \\
$\alpha-$ IR-1 & & \\
$100 \mathrm{nM}$ & $205 \pm 21$ & $1160 \pm 141$ \\
\hline
\end{tabular}

A single-cell suspension of $5 \times 10^{3}$ cells was cloned in $0.8 \%$ agarose containing IMEM, $10 \%$ calf serum, and $10 \mathrm{mM}$ Hepes. Colonies measuring $\geq 50 \mu \mathrm{m}$ were counted as described in Methods after 10-14 d. Values are the mean $\pm S E$ of triplicate determinations.

dal to the forelimb with $10^{7} \log$ phase MCF-7 or MDA-231 cells. Twice weekly intraperitoneal injections of PBS, $\alpha$-IR-3, or $\alpha$-IR-1 were started simultaneously and continued for 4-5 wk. All mice inoculated with MCF-7 cells and some with the MDA-231 cells received a 0.25mg $17 \beta$-estradiol pellet (Innovative Research, Toledo, $\mathrm{OH}$ ) implanted subcutaneously in the interscapular region. Tumor diameters were measured at regular intervals and tumor volume in cubic millimeters was calculated by the formula: volume $=(\text { width })^{2} \times$ length $/ 2$. At the end of the experiments, mice were sacrificed by cervical dislocation and blood was collected from a sectioned axillary artery. Tumors were removed, formaldehyde-fixed, sectioned, and stained with hematoxylin and eosin. Tumors were also stained for keratin, cytokeratin, epithelial membrane antigen, carcinoembrionic antigen, and collagen.

IGF-I levels and type I SR blocking activity in mouse serum. To determine immunoreactive IGF-I levels, serum was pooled from six estrogen-supplemented MCF-7 tumor-bearing mice, and from six mice with MDA-231 tumors. IGF-I levels were determined by RIA as described (20). To determine type I SR blocking activity, mouse serum was obtained $3 \mathrm{~d}$ after the last intraperitoneal administration of PBS or either antibody. Confluent monolayers of MCF-7 or MDA-231 cells in 24-well plates were preincubated with a 1:10 dilution of mouse serum for $2 \mathrm{~h}$ at $4^{\circ} \mathrm{C}$, and then washed with binding buffer. The monolayers were then incubated in binding buffer with 40 pM ${ }^{125}$ I-IGF-I for 90 min at room temperature, and cell-associated radioactivity determined as above. The number of counts per minute bound was compared to that bound to cells preincubated with control serum and expressed as percent inhibition of binding. Each sample of mouse serum was tested individually in triplicate wells.

\section{Results}

Binding experiments. In both breast cancer cell lines competitive binding studies and Scatchard analysis demonstrated that $\alpha$-IR-3 was more potent than the native hormone in inhibiting binding of ${ }^{125}$ I-IGF-I (data not shown). These binding data revealed a $K_{\mathrm{d}}$ of $0.6 \mathrm{nM}$ (MCF-7) and $2.1 \mathrm{nM}$ (MDA-231) for the receptor antibody compared with 2.9 and $4.2 \mathrm{nM}$ for IGF-I. $\alpha$-IR-1, at a concentration of $130 \mathrm{nM}$, had no effect on labeled IGF-I binding.

In vitro growth experiments. Since $\alpha$-IR-3 was an effective inhibitor of binding to the type I SR, we next determined whether this antibody-mediated receptor blockade could inhibit the growth of breast cancer cells in vitro. Anchorage-independent growth of both lines was inhibited reproducibly by $\alpha$-IR-3 in a dose-dependent fashion (Table I). A maximal effect was observed with $100 \mathrm{nM} \alpha$-IR-3, the concentration at which maximal inhibition of receptor binding was also observed. The $\alpha$-IR-1 control antibody had no inhibitory effect on colony growth.

Since colony formation in vitro requires growth in serumsupplemented medium, which contains IGF-I, the importance of endogenously secreted IGF-like activities as autocrine growth factors could not be assessed. Hence, the effects of exogenous IGF-I and $\alpha$-IR-3 on monolayer growth in serumfree medium were determined (Table II). IGF-I stimulated proliferation of both cell lines, and this effect was inhibited by $\alpha$-IR-3. In the absence of IGF-I, neither $\alpha$-IR-3 nor $\alpha$-IR-1 inhibited the growth of these cells. In some experiments $\alpha-$ IR-3 had a modest stimulatory effect on cells growing in serum-free medium.

In vivo experiments. Athymic mice were inoculated with MCF-7 or MDA-231 cells. Intraperitoneal antibody treatment was started simultaneously and continued twice weekly for 4-5 wk. After 2-3 wk each cell line produced a palpable tumor mass. Despite the fact that $\alpha$-IR-3 inhibited clonal growth of MCF-7 cells in vitro, the antibody did not block growth of these cells in vivo. In contrast, in vivo growth of MDA-231 cells was markedly inhibited (Fig. 1 and Table III). Identical

Table II. Effect of Type I SR Blockade on IGF-I-induced Growth of Human Breast Cancer Cells

\begin{tabular}{|c|c|c|c|c|}
\hline & \multicolumn{2}{|c|}{ MCF-7 } & \multicolumn{2}{|c|}{ MDA-231 } \\
\hline & Exp. No. 1 & Exp. No. 2 & Exp. No. 1 & Exp. No. 2 \\
\hline & \multicolumn{2}{|c|}{$\times 10^{-3}$ cells } & \multicolumn{2}{|c|}{$\times 10^{-3}$ cells } \\
\hline Control & $185 \pm 12$ & $191 \pm 12$ & $64 \pm 5$ & $218 \pm 17$ \\
\hline$\alpha-\operatorname{IR}-3(100 \mathrm{nM})$ & $215 \pm 12$ & $226 \pm 14$ & $91 \pm 13$ & $224 \pm 21$ \\
\hline IGF-I (13 nM) & $337 \pm 34$ & $360 \pm 12$ & $181 \pm 3$ & $413 \pm 16$ \\
\hline IGF-I $+\alpha-$ IR-3 & $249 \pm 12$ & $241 \pm 15$ & $136 \pm 11$ & $263 \pm 11$ \\
\hline$\alpha$-IR-1 (100 nM) & ND & $172 \pm 11$ & ND & $229 \pm 14$ \\
\hline IGF-I + $\alpha$-IR-1 & ND & $362 \pm 21$ & ND & $392 \pm 11$ \\
\hline
\end{tabular}

Breast cancer cells were grown in phenol red-free, serum-free IMEM alone or with IGF-I, $\alpha$-IR-1, $\alpha$-IR-3, or both hormone and antibody. Medium with hormone and/or antibody was exchanged every $2 \mathrm{~d}$. Cell counts were determined after suspending the cells with $1 \mathrm{mM}$ EDTA on day 5 . Values represent means $\pm S E$ of triplicate determinations from two separate experiments. ND, not done. 

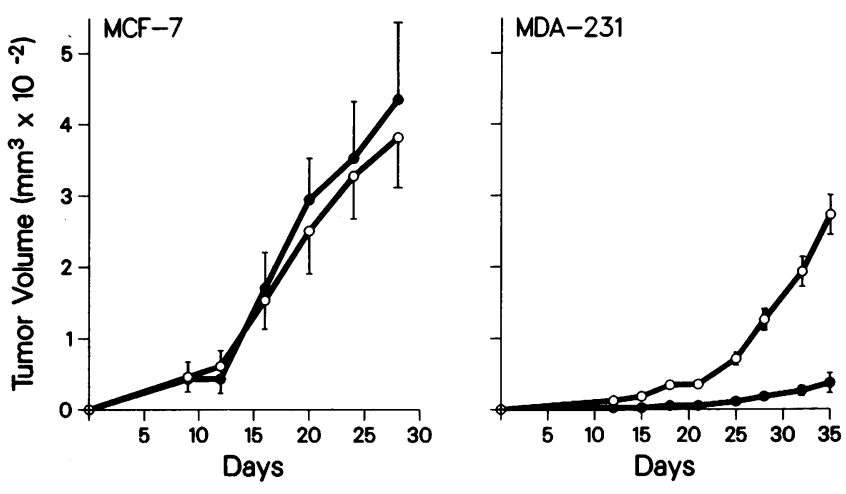

Figure 1. Effect of type I SR antibody treatment on growth of MCF-7 (left) and MDA-231 (right) tumors in athymic mice. 3-wkold female athymic mice were inoculated subcutaneously with $10^{7}$ log-phase MCF-7 or MDA-231 cells. Twice weekly intraperitoneal injections with (0) PBS or (•) $500 \mu \mathrm{g}$ of $\alpha$-IR-3 antibody were started simultaneously and continued for 4-5 wk. Tumor diameters were measured at regular intervals as specified in Methods. Each data point represents the mean $\pm \mathrm{SE}$ of six mice.

results were observed in two separate duplicate experiments. Estrogen treatment of mice carrying MDA-231 tumors had no effect on tumor growth, and it did not prevent inhibition by $\alpha$-IR-3 (not shown).

The inhibitory effect on the ER-negative MDA-231 tumors was dose dependent (Fig. 2, left). A maximal effect was observed with $500 \mu \mathrm{g}$ per injection of $\alpha$-IR-3. At this dose, the tumor take rate was only $50 \%$ (only three of six inoculated mice formed a small palpable tumor) (Table III). Intermediate levels of inhibition were observed with doses ranging between 2 and $200 \mu \mathrm{g}$ per injection. The $\alpha$-IR-1 control antibody (Fig. 2, right) had no effect on MDA-231 tumor growth in doses ranging from 2 to $200 \mu \mathrm{g}$.
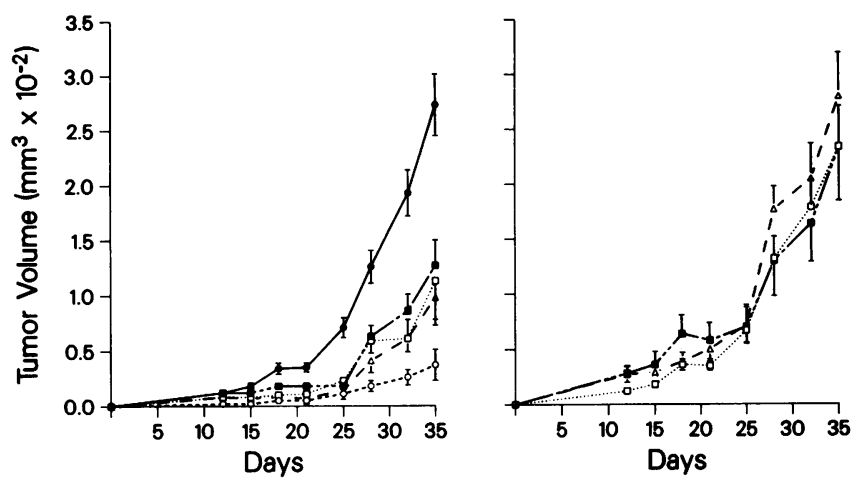

Figure 2. Effect of $\alpha$-IR-3 and $\alpha$-IR-1 on growth of MDA-231 tumors in athymic mice. MDA-231 cells were implanted in athymic mice as described in Fig. 1 and injected twice weekly intraperitoneally for 5 wk with PBS (๑) or with different doses of $\alpha$-IR-3 (left) or

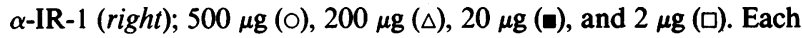
data point represents the mean $\pm \mathrm{SE}$ of six mice.

Tumor sections stained with hematoxylin and eosin revealed marked fibrosis, tumor cell loss, and the appearance of numerous spindle-shaped cells in the $\alpha$-IR-3-treated MDA-231 tumors but not in the controls treated with $\alpha$-IR-1 (Fig. 3). Most of the spindle-shaped cells were cytologically malignant and stained for epithelial markers (keratin, cytokeratin, epithelial membrane antigen, and carcinoembrionic antigen); some were cytologically benign, lacked epithelial markers, and were consistent with mouse fibroblasts. A mononuclear cell infiltrate was not observed in any of the sections. A tri-elastin stain revealed marked deposition of collagen in the $\alpha$-IR-3-treated MDA-231 tumors (not shown). These histologic changes were not present in the MCF-7 tumors from

Table III. Inhibition of Breast Tumor Formation and Growth in Nude Mice Treated with $\alpha-I R-3$ and $\alpha-I R-I$

\begin{tabular}{|c|c|c|c|c|c|c|}
\hline Cell line & Treatment & Dose & Tumor formation* & Tumor size & Tumor weight & $\begin{array}{c}\text { Type I SR } \\
\text { blocking activity } \\
\text { in serum }\end{array}$ \\
\hline & & $\mu g$ & & $\mathrm{~mm}^{3}$ & $m g$ & $\%$ \\
\hline \multirow[t]{2}{*}{ MCF-7 } & PBS & - & $6 / 6$ & $381 \pm 70$ & ND & 0 \\
\hline & $\alpha$-IR-3 & 500 & $6 / 6$ & $434 \pm 149$ & ND & $66 \pm 0.8$ \\
\hline \multirow[t]{8}{*}{ MDA-231 } & PBS & - & $6 / 6$ & $273 \pm 28$ & $177 \pm 26$ & 0 \\
\hline & $\alpha$-IR-3 & 2 & $6 / 6$ & $113 \pm 40$ & $77 \pm 18$ & $23 \pm 3$ \\
\hline & & 20 & $6 / 6$ & $127 \pm 23$ & $75 \pm 11$ & $54 \pm 0.7$ \\
\hline & & 200 & $5 / 6$ & $98 \pm 20$ & $89 \pm 11$ & $57 \pm 0.6$ \\
\hline & & 500 & $3 / 6$ & $37 \pm 14$ & $41 \pm 10$ & $59 \pm 1$ \\
\hline & $\alpha$-IR-1 & 2 & $6 / 6$ & $234 \pm 37$ & $179 \pm 26$ & 0 \\
\hline & & 20 & $6 / 6$ & $234 \pm 49$ & $155 \pm 31$ & 0 \\
\hline & & 200 & $6 / 6$ & $280 \pm 40$ & $198 \pm 48$ & $3 \pm 1$ \\
\hline
\end{tabular}

Athymic mice were inoculated with MCF-7 or MDA-231 cells. Treatment with PBS or antibody was started simultaneously and continued twice weekly thereafter for 4 (MCF-7) or 5 (MDA-231) wk, at which time tumor formation, volume, weight, and histology were evaluated. To determine serum type I SR blocking activity, confluent monolayers of MCF-7 or MDA-231 cells were preincubated with a 1:10 dilution of mouse serum, washed, and then incubated with ${ }^{125}$ I-IGF-I as described in Methods. The number of counts per minute bound was compared to that bound to cells not preincubated with serum and expressed as percent inhibition of binding. Each individual mouse serum sample was tested in triplicate wells. All data are presented as the mean $\pm \mathrm{SE}$ of six animals per each dose. ND, not done. * Number of animals in which tumors formed per total number of animals inoculated with tumor cells. 

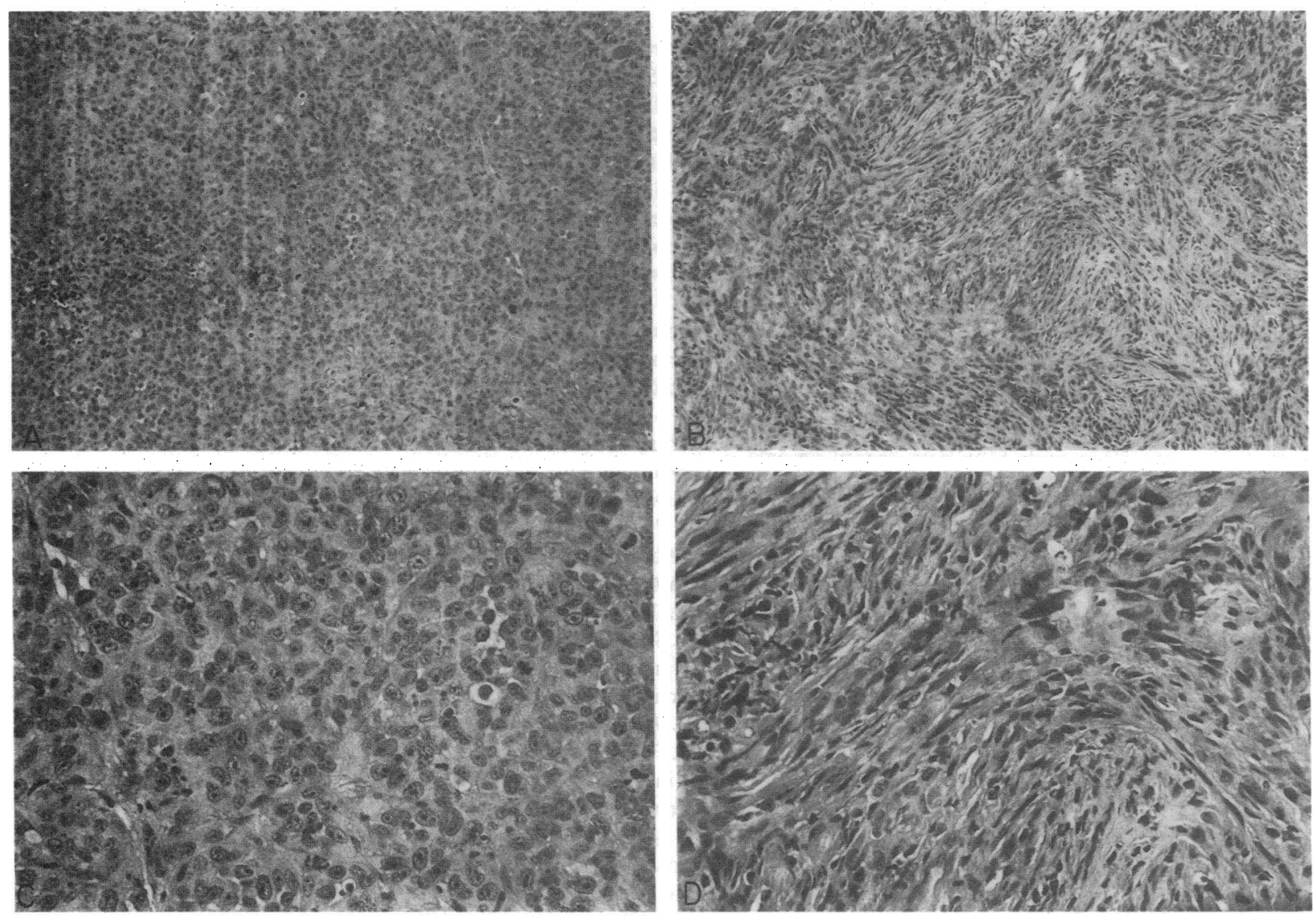

Figure 3. Histology of $\alpha$-IR-1- and $\alpha$-IR-3-treated MDA-231 tumors. Nude mice were implanted with MDA-231 cells and injected intraperitoneally twice weekly for $5 \mathrm{wk}$ with $200 \mu \mathrm{g}$ of $\alpha$-IR-1 $(A$ and $C$ ) or $500 \mu \mathrm{g}$ of $\alpha$-IR-3 antibody $(B$ and $D$ ). On day 35, tumors were removed, formaldehyde-fixed, sectioned, and stained with hematoxylin and eosin. Upper panels were photographed at $\times 125$ and lower panels at $\times 1,000$.

mice treated with either $\alpha$-IR-3 or $\alpha$-IR-1. A complete necropsy in the control and $\alpha$-IR-3 treated mice was otherwise normal.

IGF-I levels and type I SR blocking activity in mouse serum. Differences in the inhibitory effects of $\alpha$-IR-3 on MCF-7 and MDA-231 tumors were not due to differences in either type I SR blocking activity or in IGF-I levels in mouse serum. As shown in Table III, type I SR blocking activity was not detected in serum from mice with either MCF-7 or MDA-231 tumors treated with PBS or $\alpha$-IR-1. In contrast, the mice treated with $\alpha$-IR-3 exhibited significant dose-dependent receptor blocking activity in their serum. Similar levels of receptor blocking activity were achieved in mice with either MCF-7 or MDA-231 tumors treated with $500 \mu \mathrm{g}$ of $\alpha$-IR-3. Still, growth of the MCF-7 tumors was not affected.

Immunoreactive IGF-I levels were also similar in both groups of mice. IGF-I levels, by RIA, were 65 and $68 \mathrm{ng} / \mathrm{ml}$ in pooled sera from estrogen-supplemented MCF-7 tumor-bearing mice and from mice with MDA-231 tumors, respectively (Merimee, T. J., personal communication).

\section{Discussion}

In this study we have reported the effect of blockade of the type I SR on in vitro and in vivo growth of human breast cancer cells. This receptor may mediate at least partially the mitogenic effect of insulin, IGF-I, and IGF-II on these cells. In the presence of serum, anchorage-independent growth of both MCF-7 and MDA-231 cell lines was inhibited by $\alpha$-IR-3. A similar inhibitory effect by this antibody on monolayer growth of MCF-7 cells in medium containing calf serum has been reported (21). Under serum-free conditions, antibody-induced receptor blockade either had no net effect or in some experiments slightly stimulated growth, thereby making it difficult to evaluate the possible autocrine role of secreted IGF-like activities on breast cancer cell proliferation by means of this model. The mechanisms mediating this mild stimulatory effect, also observed in Chinese hamster ovary cells transfected with the IGF-I receptor (22), are currently unclear. However, utilizing a panel of five additional human breast cancer cell lines, we have not observed growth stimulation (or inhibition) with alphaIR-3 under serum-free conditions (Arteaga, C. L., and C. K. Osborne, manuscript submitted for publication).

In the nude mouse model, antibody-induced blockade of the type I SR inhibited growth of the estrogen-independent MDA-231 cells in a dose-dependent fashion. It seems unlikely that the inhibitory effect of $\alpha$-IR-3 was mediated by modulation of the host immune mechanisms in these athymic mice since growth inhibition was not observed when a control antibody was administered, and since a mononuclear cell infiltrate was not observed in any of the tumor histologic sections. 
Despite similar levels of type I SR blocking activity and of immunoreactive IGF-I levels in serum from mice inoculated with MCF-7 cells, growth of the MCF-7 tumors was unaffected by treatment with the anti-receptor antibody. There are several possible explanations for the loss of sensitivity of the MCF-7 cells to $\alpha$-IR-3 when grown in vivo. First, it is possible that estrogen is the major growth factor for the ER-positive MCF-7 cells and that its effects override those mediated by the IGFs. It is also possible that other estrogen-induced growth promoting activities (i.e., epidermal growth factor [EGF]-like peptides) $(23,24)$ made by the MCF-7 cells compensate for the type I SR blockade. Experiments using combinations of antibodies against different growth factors or their receptors may address that possibility. Secondly, it is conceivable that the MCF-7 cells lose the type I SR in vivo. However, recent reports indicate a stimulatory effect of exogenous IGF-I on MCF-7 tumor growth in nude mice (23), suggesting that these cells maintain their type I somatomedin receptors in vivo. Furthermore, breast cancer cells from patient biopsies also express type I somatomedin receptors (16). Thirdly, it is possible that estrogen supplementation induced a marked increase in IGF-I secretion by other mouse organs, and that this secretion was able to counteract the inhibitory effect of $\alpha$-IR-3. However, we found no difference in serum receptor blocking activity or in serum IGF-I levels between mice receiving estrogen supplementation and those that were estrogen-deprived. Moreover, the MDA-231 cells secrete constitutively higher levels of an IGF-I-like protein (3) and are still inhibited by the type I SR antibody. Finally, estrogen supplementation did not prevent the growth inhibition of MDA-231 tumors in vivo.

In summary, these studies show that antagonism of the type I SR with an antibody inhibits growth of human breast cancer cells in vitro. In addition, in an athymic mouse model, receptor blockade inhibits in vivo growth of the estrogen-independent MDA-231 breast cancer cells, suggesting that IGFs may be important in vivo growth regulators for some human breast cancers. The potential toxicity of in vivo blockade of the type I SR will require additional studies. This toxicity could not be assessed in this model since the antibody does not cross react with mouse receptors. This is the first report demonstrating that interruption of a polypeptide growth factor pathway in vivo can alter growth of breast cancer. Other reports have shown that in vivo blockade of the EGF receptor (25) or antibody neutralization of bombesin (26), a possible autocrine growth factor, can inhibit growth of other tumors. These data suggest that antagonism of polypeptide growth factors may offer a new strategy for "endocrine" therapy of breast cancer.

\section{Acknowledgments}

We thank Dr. Thomas J. Merimee, University of Florida, Gainesville, for the RIA of IGF-I in mouse serum. The secretarial assistance of Mrs. Pamela Render is greatly appreciated.

This study was supported by National Institutes of Health grants R01 CA-30251 (C.K.O.) and P01 30195 (C.K.O.) and a Veterans Administration Associate Investigator Career Development Award (Dr. Arteaga).

\section{References}

1. Osborne, C. K., G. Bolan, M. E. Monaco, and M. E. Lippman. 1976. Hormone responsive human breast cancer in long-term tissue culture: effect of insulin. Proc. Natl. Acad. Sci. USA. 73:4536-4540.
2. Gross, G. E., D. H. Boldt, and C. K. Osborne. 1984. Perturbation by insulin of human breast cancer cell cycle kinetics. Cancer Res. 44:3570-3575.

3. Furlanetto, R. W., and J. N. DiCarlo. 1984. Somatomedin-C receptors and growth effects in human breast cancer cells maintained in long term tissue culture. Cancer Res. 44:2122-2128.

4. Myal, Y., R. P. C. Shiu, B. Bhaumick, and M. Bala. 1984. Receptor binding and growth-promoting activity of insulin-like growth factors in human breast cancer cells (T47D) in culture. Cancer Res. 44:5486-5490.

5. Huff, K. K., D. Kaufman, K. H. Gabbay, E. M. Spencer, M. E. Lippman, and R. B. Dickson. 1986. Secretion of an insulin-like growth factor-I-related protein by human breast cancer cells. Cancer Res. 46:4613-4619.

6. Coronado, E., K. Ramasharma, C. H. Li, L. Kitten, M. Marshall, S. Fuqua, and K. Osborne. 1988. Insulin-like growth factor II (IGF-II): a potential autocrine growth factor for human breast cancer. Proc. Am. Assoc. Cancer Res. 29:237. (Abstr.)

7. Minuto, F., P. Del Monte, A. Barreca, A. Nicolin, and G. Giordano. 1987. Partial characterization of somatomedin C-like immunoreactivity secreted by breast cancer cells in vitro. Mol. Cell. Endocrinol. 54:179-184.

8. Dickson, R. B., and M. E. Lippman. 1987. Estrogenic regulation of growth and polypeptide growth factor secretion in human breast carcinoma. Endocr. Rev. 8:29-43.

9. Huff, K. K., C. Knabbe, R. Lindsey, D. Kaufman, D. Bronzert, M. E. Lippman, and R. B. Dickson. 1988. Multihormonal regulation of insulin-like growth factor-I-related protein in MCF-7 human breast cancer cells. Mol. Endocrinol. 2:200-208.

10. Yu, K.-T., and M. P. Czech. 1984. The type I insulin-like growth factor receptor mediates the rapid effect of multiplication stimulating activity on membrane transport systems in rat soleus muscle. $J$. Biol. Chem. 259:3090-3095.

11. Van Wyk, J. J., D. C. Graves, S. J. Casella, and S. Jacobs. 1985. Evidence from monoclonal antibody studies that insulin stimulates deoxyribonucleic acid synthesis through the type I somatomedin receptor. J. Clin. Endocrinol. Metab. 61:639-643.

12. Flier, J. S., P. Usher, and A. C. Moses. 1986. Monoclonal antibody to the type I insulin-like growth factor (IGF-I) receptor blocks IGF-I receptor-mediated DNA synthesis: clarification of the mitogenic mechanisms of IGF-I and insulin in human skin fibroblasts. Proc. Natl. Acad. Sci. USA. 83:664-668.

13. Catanese, V. M., F. Grigorescu, G. L. King, and R. C. Kahn. 1986. The human erythrocyte insulin-like growth factor I receptor: characterization and demonstration of ligand-stimulated autophosphorylation. J. Clin. Endocrinol. Metab. 62:692-699.

14. Furlanetto, R. W., J. N. DiCarlo, and C. Wisehart. 1987. The type II insulin-like growth factor receptor does not mediate deoxyribonucleic acid synthesis in human fibroblasts. J. Clin. Endocrinol. Metab. 64:1142-1149.

15. Ewton, D. Z., S. L. Falen, and J. R. Florini. 1987. The type II insulin-like growth factor (IGF) receptor has low affinity for IGF-I analogs: pleiotypic actions of IGFs on myoblasts are apparently mediated by the type I receptor. Endocrinology. 120:115-123.

16. Pekonen, F., S. Partanen, T. Mäkinen, and E.-M. Rutanen. 1988. Receptors for epidermal growth factor and insulin-like growth factor I and their relation to steroid receptors in human breast cancer. Cancer Res. 48:1343-1347.

17. Arteaga, C. L., A. K. Tandon, D. D. Von Hoff, and C. K. Osborne. 1988. Transforming growth factor $\beta$ : potential autocrine growth inhibitor of estrogen receptor-negative human breast cancer cells. Cancer Res. 48:3898-3904.

18. Kull, F. C., S. Jacobs, Y.-F. Su, M. E. Svoboda, J. J. Van Wyk, and P. Cuatrecasas. 1983. Monoclonal antibodies to receptor for insulin and somatomedin-C. J. Biol. Chem. 258:6561-6566.

19. Jacobs, S., S. Cook, M. E. Svoboda, and J. J. Van Wyk. 1986. Interaction of the monoclonal antibodies alpha-IR-1 and alpha-IR-3 
with insulin and somatomedin-C receptors. Endocrinology. 118:223226.

20. Merimee, T. J., J. Zapf, B. Hewelett, and L. L. Cavalli-Sforza. 1987. Insulin-like growth factors in pygmies: the role of puberty in determining final stature. N. Engl. J. Med. 316:906-911.

21. Rohlik, Q. T., D. A. Adams, F. C. Kull, and S. Jacobs. 1987. An antibody to the receptor for insulin-like growth factor-I inhibits the growth of MCF-7 cells in tissue culture. Biochem. Biophys. Res. Commun. 149:276-281.

22. Steele-Perkins, G., J. Turner, J. C. Edman, J. Hori, S. B. Pierce, C. Stover, W. J. Rutter, and R. A. Roth. 1988. Expression and characterization of a functional human insulin-like growth factor I receptor. J. Biol. Chem. 263:11486-11492.

23. Dickson, R. B., M. E. McManaway, and M. E. Lippman. 1986.
Estrogen-induced factors of breast cancer cells partially replace estrogen to promote tumor growth. Science (Wash. DC). 232:1540-1543.

24. Bates, S. E., N. E. Davidson, E. M. Valverius, C. E. Freter, R. B. Dickson, J. P. Tam, J. E. Kudlow, M. E. Lippman, and D. S. Salomon. 1988. Expression of transforming growth factor alpha and its messenger ribonucleic acid in human breast cancer: its regulation by estrogen and its possible functional significance. Mol. Endocrinol. 2:543-555.

25. Masui, H., T. Kawamoto, J. D. Sato, B. Wolf, G. Sato, and J. Mendelsohn. 1984. Growth inhibition of human tumor cells in athymic mice by anti-epidermal growth factor receptor monoclonal antibodies. Cancer Res. 44:1002-1007.

26. Cuttitta, F., D. N. Carney, J. Mulshine, T. W. Moody, J. Fedorko, A. Fischler, and J. D. Minna. 1985. Bombesin-like peptides can function as autocrine growth factors in human small-cell lung cancer. Nature (Lond.). 316:823-826. 